\title{
Is the use of antibiotic-impregnated external ventricular drainage beneficial in the management of iatrogenic ventriculitis?
}

\author{
Jehuda Soleman • Serge Marbacher • Javier Fandino • \\ Ali Reza Fathi
}

Received: 6 June 2011 / Accepted: 29 August 2011 /Published online: 18 September 2011

(C) Springer-Verlag 2011

\begin{abstract}
Background Profound evidence substantiates significantly reduced risk of catheter-related infections with prophylactic use of rifampin- and clindamycin-impregnated silicone catheters (Bactiseal ${ }^{\circledR}$, Codman Johnson \& Johnson, Raynham, MA, USA) for external ventricular drainage (EVD). However, whether Bactiseal ${ }^{\circledR}$-EVD (B-EVD) influences the treatment of EVD-related ventriculitis remains controversial.

Methods We performed a retrospective analysis of patients who developed ventriculitis after EVD or ventriculoperitoneal (VP) shunt placement and consequently underwent either placement of B-EVD (group 1) or a standard non-antibioticimpregnated EVD (group 2). Analyzed parameters included demographic and clinical data, hospitalization time, time until remission of the infection parameters, detection of new bacterial resistance on antibiograms, and clinical outcome in terms of the modified Rankin scale (mRS).

Results Time until remission of cerebrospinal fluid (CSF) pleocytosis was significantly longer in patients undergoing BEVD ( $8 \pm 3.8$ days; $n=15$; group 1$)$ than in patients who underwent standard EVD (5.1 \pm 1.8 days; $n=10$; group 2$)$. There was no significant difference between both groups for the time until polymorphonuclear cells dropped below $50 \%$ of peak value (5.8 \pm 1.6 vs. $4.1 \pm 2.9$ days), CRP dropped
\end{abstract}

J. Soleman · S. Marbacher · J. Fandino · A. R. Fathi $(\bowtie)$

Department of Neurosurgery, Kantonsspital Aarau,

Tellstrasse, 5001 Aarau, Switzerland

e-mail: AR.Fathi@gmx.net

S. Marbacher $\cdot$ J. Fandino $\cdot$ A. R. Fathi

Department of Intensive Care Medicine and Neurosurgery,

Bern University Hospital and University of Bern,

Bern, Switzerland below $10 \mathrm{mg} / 1(4.2 \pm 3.5$ vs. $5.6 \pm 3.3$ days $)$, the time of plasma neutrophil remission ( $5.7 \pm 2.6$ vs. $5.3 \pm 3.2$ days) and hospitalization time ( $28 \pm 12.5$ vs. $35 \pm 19.4$ days). The mRS for both groups was 2. Development of new antibiotic resistance did not occur in either group.

Conclusions This retrospective pilot study indicates that BEVD might have no major advantage in the management of EVD or VP-shunt-related ventriculitis. Based on published reports and the results of this study, data support only the prophylactic use of B-EVD for prevention of EVD-related infections. Prospective randomized clinical trials are warranted to further evaluate the role of B-EVD in the treatment of ventriculitis.

Keywords Ventricular drainage - Ventriculitis . Hydrocephalus · Infection

\section{Introduction}

Rifampin- and clindamycin-impregnated silicone catheters (Bactiseal ${ }^{\circledR}$ ) for external ventricular drainage (EVD) were developed to prevent cerebrospinal fluid (CSF) infections. Various studies, including a prospective, randomized, controlled trial [13], have shown a significantly reduced risk of catheter-related infections with the use of BactisealEVD (B-EVD) [6, 8, 13]. Standard therapy with nonantibiotic-impregnated EVD is known to have a high rate of infection (5-20\%) [2, 4-6, 9-11, 13]. Standard treatment of CSF infection following EVD or VP shunt placement consists of removal and/or exchange of the catheter and broadspectrum intravenous antibiotic agents until verification of cultures [7]. Despite extensive data on the efficacy of B-EVD in the prevention of CSF infections, it is still not clearly 
Table 1 Course of infection parameters $(C R P \mathrm{C}$-reactive protein)

\begin{tabular}{llll}
\hline & $\begin{array}{l}\text { Group 1; } \\
\text { Standard EVD }\end{array}$ & $\begin{array}{l}\text { Group 2; } \\
\text { B-EVD }\end{array}$ & \\
\hline Time until remission of pleocytosis (days) & 5.1 & 8 & $p=0.044$ \\
Time until polymorphonuclear cells $<50 \%$ (days) & 4.1 & 5.8 & n.s. \\
Time until plasma neutrophils $<10$ (days) & 5.3 & 5.7 & n.s. \\
Time until CRP $<10$ (days) & 5.6 & 4.2 & n.s. \\
\hline
\end{tabular}

defined whether B-EVD is beneficial after a CSF infection has occurred.

The aim of our study was to analyze the efficacy of B-EVD compared to standard non-antibiotic-impregnated EVD in the treatment of EVD- and VP-shunt-related ventriculitis.

\section{Methods}

We performed a retrospective analysis of patients who received a B-EVD (Codman, Johnson \& Johnson, Raynham, MA, USA) following the diagnosis of iatrogenic ventriculitis between 2005 and 2006 (group 1), and compared the data to a patient cohort that received standard non antibioticimpregnated EVD (Dispomedica GmbH, Hamburg, Germany) between 2003 and 2005 (group 2). Diagnosis of iatrogenic ventriculitis required at least one criterion A plus two criterions B. A criterions were: fever $>38.5^{\circ} \mathrm{C}$, meningitis, irritability, new neurologic deficit, decreased Glasgow Coma Scale, increased white blood cells, increased CRP. B criterions were: increased CSF white cells $>300 / \mathrm{mm}^{2}$ (predominantly polymorphonuclear cells), elevated CSF protein and/or decreased glucose, positive CSF Gram staining, positive CSF cultures.

Patients in both groups received broad-spectrum intravenous antibiotics until the microorganisms were identified in cultures and the antibiogram results were completed. The antibiotic regimen was then specifically targeted until cultures were negative and clinical parameters of infection were in a normal range.

The following data were acquired for statistical analyses: demographic and clinical data, hospitalization time, time until remission of the infection parameters, detection of new bacterial resistance after insertion of a B-EVD on antibiograms, and clinical outcome using the mRS. Patients with incomplete patient records and patients with initial Gram- negative infections were excluded from the analysis, since BEVD is ineffective in treating Gram-negative infections.

Analysis of the final data set was performed using JMP software (SAS Institute Inc., Cary NC, USA). Values were expressed as mean $\pm \mathrm{SD}$. A $p$ value $<0.05$ was considered significant.

\section{Results}

Twenty-five patients (13 male, 12 female) were included in the study (15 in group 1, ten in group 2). The mean ages in groups 1 and 2 were $51.5 \pm 11.4$ years and $50 \pm 19.8$ years, respectively. Patients in group 1 underwent ventriculostomy for EVD due to subarachnoid hemorrhage $(n=6)$, normal pressure hydrocephalus $(n=2)$, intraventricular hemorrhage $(n=1)$ and congenital hydrocephalus $(n=1)$. EVD became necessary in group 2 due to subarachnoid hemorrhage ( $n=$ $10)$, normal pressure hydrocephalus $(n=2)$, congenital hydrocephalus $(n=2)$ and obstructive hydrocephalus $(n=1)$.

We observed that time to remission of pleocytosis was significantly longer in group 1 ( $8 \pm 3.8$ days) than in group 2 $(5.1 \pm 1.8$ days $)(p<0.05)$. The polymorphonuclear cells decreased below $50 \%$ of peak value significantly faster in group 1 than in group 2 ( $4.1 \pm 2.9$ vs. $5.8 \pm 1.6$ days; $p<0.05)$. There were no significant differences between group 1 and group 2 for the time until plasma neutrophil remission $(5.7 \pm$ 2.6 vs. $5.3 \pm 3.2$ days) and for the time until C-reactive protein (CRP) dropped below $10 \mathrm{mg} / \mathrm{l}$ (4.2 \pm 3.5 vs. $5.6 \pm$ 3.3 days). An overview of the course of laboratory infection parameters in both groups is given in Table 1 .

The length of hospitalization from the diagnosis of EVD-related ventriculitis until discharge was $28 \pm 12.5$ days in group 1 and $35 \pm 19.4$ days in group 2 (n.s.). The mRS of both groups was 2 (Table 2).
Table 2 Comparison of hospitalization time in days and $\mathrm{mRS}$

\begin{tabular}{llll}
\hline & Group 1; Standard EVD & Group 2; B-EVD & \\
\hline Hospitalization time (days) & 35 & 28 & n.s. \\
Modified Rankin scale & 2 & 2 & n.s. \\
\hline
\end{tabular}


The analysis of the clinical data and antibiograms for the BEVD revealed no development of new antibiotic resistance.

\section{Discussion}

CSF infections, i.e., meningitis and ventriculitis, are the most common complications caused by EVD and VP shunts [4]. They are associated with increased morbidity, mortality, and hospitalization time [13]. Concerns regarding the risks of CSF infection have led to widespread use of prophylactic antibiotic agents in the treatment of patients with EVD catheters. It has been shown that prophylaxis with a single broad-spectrum antibiotic agent (cefepime) was an effective alternative to dual-specific antibiotic treatment with ampicillin/sulbactam and aztrenam for patients with an EVD in situ [12]. An additional study demonstrated almost identical rates of CSF infection in patients who received prophylactic antibiotics throughout the period the EVD catheter was in place $(3.8 \%)$ compared to patients who received only periprocedural antibiotics (4\%) [1]. However, evidence-based guidelines for prophylactic antibiotic (PAB) administration do not yet exist, and the effectiveness of PAB was not proven in a randomized, placebo-controlled, multicenter, double-blind study [7]. Given the clinical results with central line catheters impregnated with antibiotic agents [3] and the lack of data on PAB effectiveness, clinical trials with impregnated EVD catheters were conducted. It has been shown that with prophylactic use of BEVD, risk of catheter-related infections can be significantly reduced [6, 13]. The standard treatment for CSF infections due to EVD or VP shunt insertion is changing the drainage system and treatment with antibiotic agents. To date, there is no study comparing insertion of B-EVD with non-antibioticimpregnated EVD in the management of EVD- or VP-shuntassociated CSF infection.

In the presented study, we analyzed the efficacy of B-EVD compared to standard EVD in the course of iatrogenic ventriculitis (EVD-related infections, VP shunt infections). One would expect greater efficacy using B-EVD, since it has been proven to significantly reduce catheter-related infections. Surprisingly, our study demonstrated no significant differences in the efficacy of treatment with B-EDV and standard EVD, in terms of parameters related to the course of infection (with the exception of remission of pleocytosis), hospitalization time, and outcome.

Despite the limited number of patients, our study suggests that there is limited benefit in using B-EVD for the management of iatrogenic ventriculitis. Additionally, in the BEVD group, the period until normalization of CSF pleocytosis is significantly longer $(p<0.05)$, suggesting that the duration of the infection is not shortened by B-EVD. All other infection parameters analyzed (time of plasma neutrophil remission, decrease in polymorphonuclear cells below 50\% of peak value, and time until CRP dropped below $10 \mathrm{mg} / \mathrm{l}$ ) showed no significant difference. The hospitalization time of patients treated with B-EVD tends to be shorter, but not significantly.

The costs of B-EVD exceed those of standard EVD by $44.1 \%$. In addition, the hospitalization time of patients treated with B-EVD tends to be shorter (mean hospitalization time B-EVD group 28 \pm 12.5 , standard EVD group $35 \pm$ 19.4 days), but not significantly. Therefore, we assume that the usage of B-EVD in the management of iatrogenic ventriculitis might not have an economical advantage compared to standard EVD.

Antimicrobial resistance is an issue of potential concern with the use of impregnated catheters. Although there is no evidence that such resistance has resulted from central venous line catheters, continued surveillance for antibiotic resistance is required [3, 13]. None of the patients in our study treated with B-EVD showed new antibiotic resistance.

In conclusion, this retrospective pilot study indicates that B-EVD has no major advantage over non-antibioticimpregnated catheters in the management of EVD-related ventriculitis. Based on these findings, the indication for use of B-EVD remains prevention rather than management of EVD-associated infections. Prospective randomized clinical trials are warranted to further evaluate the effect of B-EVD in the management of iatrogenic ventriculitis.

Conflicts of interest None.

\section{References}

1. Alleyne CH Jr, Hassan M, Zabramski JM (2000) The efficacy and cost of prophylactic and perioprocedural antibiotics in patients with external ventricular drains. Neurosurgery 47:1124-1127, discussion $1127-1129$

2. Camacho EF, Boszczowski I, Basso M, Jeng BC, Freire MP, Guimaraes T, Teixeira MJ, Costa SF (2011) Infection rate and risk factors associated with infections related to external ventricular drain. Infection 39:47-51

3. Darouiche RO, Raad II, Heard SO, Thornby JI, Wenker OC, Gabrielli A, Berg J, Khardori N, Hanna H, Hachem R, Harris RL, Mayhall G (1999) A comparison of two antimicrobial-impregnated central venous catheters. Catheter Study Group. N Engl J Med 340:1-8

4. Hoefnagel D, Dammers R, Ter Laak-Poort MP, Avezaat CJ (2008) Risk factors for infections related to external ventricular drainage. Acta Neurochir (Wien) 150:209-214, discussion 214

5. Mayhall CG, Archer NH, Lamb VA, Spadora AC, Baggett JW, Ward JD, Narayan RK (1984) Ventriculostomy-related infections. A prospective epidemiologic study. N Engl J Med 310:553-559

6. Muttaiyah S, Ritchie S, John S, Mee E, Roberts S (2010) Efficacy of antibiotic-impregnated external ventricular drain catheters. J Clin Neurosci 17:296-298 
7. Prabhu VC, Kaufman HH, Voelker JL, Aronoff SC, Niewiadomska-Bugaj M, Mascaro S, Hobbs GR (1999) Prophylactic antibiotics with intracranial pressure monitors and external ventricular drains: a review of the evidence. Surg Neurol 52:226-236, discussion 236-227

8. Rivero-Garvia M, Marquez-Rivas J, Jimenez-Mejias ME, Neth O, Rueda-Torres AB (2011) Reduction in external ventricular drain infection rate. Impact of a minimal handling protocol and antibiotic-impregnated catheters. Acta Neurochir (Wien) 153:647-651

9. Scheithauer S, Burgel U, Bickenbach J, Hafner H, Haase G, Waitschies B, Reinges MH, Lemmen SW (2010) External ventricular and lumbar drainage-associated meningoventriculitis: prospective analysis of time-dependent infection rates and risk factor analysis. Infection 38:205-209

10. Scheithauer S, Burgel U, Ryang YM, Haase G, Schiefer J, Koch S, Hafner H, Lemmen S (2009) Prospective surveillance of drain associated meningitis/ventriculitis in a neurosurgery and neurological intensive care unit. J Neurol Neurosurg Psychiatry 80:1381-1385

11. Sonabend AM, Korenfeld Y, Crisman C, Badjatia N, Mayer SA, Connolly ES, Jr. (2011) Prevention of ventriculostomy-related infections with prophylactic antibiotics and antibiotic-coated external ventricular drains: a systematic review. Neurosurgery. Epub ahead of print

12. Wong GK, Poon WS, Lyon D, Wai S (2006) Cefepime vs Ampicillin/Sulbactam and Aztreonam as antibiotic prophylaxis in neurosurgical patients with external ventricular drain: result of a prospective randomized controlled clinical trial. J Clin Pharm Ther 31:231-235

13. Zabramski JM, Whiting D, Darouiche RO, Horner TG, Olson J, Robertson C, Hamilton AJ (2003) Efficacy of antimicrobialimpregnated external ventricular drain catheters: a prospective, randomized, controlled trial. J Neurosurg 98:725-730

\section{Comment}

The assumption that the use of EVD catheters impregnated with antibiotics - supported logically by the industry - can significantly reduce the risk of catheter-related infections has progressively been established in last decades. Nevertheless, it was recently demonstrated that the risk of false-negative culture results may be increased when a CSF sample is drawn through an antibiotic impregnated catheter. In fact, when managing a known shunt infection, a false-negative result from an EVD culture specimen may lead to an inappropriate duration and type of antibiotic therapy, certainly playing a noteworthy role in the actual emergence of resistant bacteria. The present well-written retrospective study, despite the small number of patients, provides considerable clinical implications, mostly related to the widespread use of antibiotic-impregnated drains and the current high rates of shunt reinfection after EVD use worldwide. Particularly interesting is the fact that there were no significant differences in the efficacy of treatment with antibiotics-impregnated EDV and standard EVD, in terms of parameters related to the course of infection (except for remission of pleocytosis), hospitalization time, and outcome. These results are similar to our personal observations. In fact, in a consecutive series of 29 patients with antibiotics-impregnated EVD compared to a comparable control group, we have documented analogous results. The authors should be complimented for their efforts in reporting their experience in this, often-neglected, field; this study should be considered for future prospective randomized clinical trials in further evaluating the real advantages (or disadvantages) of the antibiotic-impregnated catheters.

\section{Alex Alfieri}

Christian Marquart

Halle-Wittenberg, Germany 